\title{
Healthcare model with use of information and communication technology for patients with chronic disease
}

\author{
Mira Lisiecka-Biełanowicz' ${ }^{1}$ Zbigniew M. Wawrzyniak ${ }^{1,2}$ \\ ${ }^{1}$ Department of the Prevention of Environmental Hazards and Allergology, Faculty of Health Sciences, Medical University \\ of Warsaw, Warsaw, Poland \\ 2 ISE, Faculty of Electronics and Information Technology, Warsaw University of Technology, Warsaw, Poland \\ Lisiecka-Biełanowicz M, Wawrzyniak ZM. Healthcare model with use of information and communication technology for patients with chronic \\ disease. Ann Agric Environ Med. 2016; 23(3): 462-467. doi: 10.5604/12321966.1219188
}

\section{Abstract}

Introduction and objective. The healthcare system is positioned in the patient's environment and works with other determinants of the treatment. Patient care requires a whole system compatible to the needs of organizational and technical solutions. The purpose of this study is to present a new model of patient-oriented care, in which the use of information and communication technology (ICT) can improve the effectiveness of healthcare for patients with chronic diseases.

Material and methods. The study material is the process of healthcare for chronically ill patients. Knowledge of the circumstances surrounding ecosystem and of the patients' needs, taking into account the fundamental healthcare goals allows us to build a new models of care, starting with the economic assumptions. The method used is modeling the construction of efficient healthcare system with the patient-centered model using ICT tools.

Results. We present a new systemic concept of building patient's environment in which he is the central figure of the healthcare organization - so called patient centered system. The use of ICT in the model of chronic patient's healthcare can improve the effectiveness of this kind of care. The concept is a vision to making wide platform of information management in chronic disease in a real environment ecosystem of patient using ICT tools.

Conclusions. On the basis of a systematic approach to the model of chronic disease, and the knowledge of the patient itself, a model of the ecosystem impacts and interactions through information feedback and the provision of services can be constructed. ICT assisted techniques will increase the effectiveness of patient care, in which nowadays information exchange plays a key role.

\section{Key words}

healthcare system, chronic disease, organizational model, health information management, ICT systems

\section{INTRODUCTION}

In tackling chronic disease, healthcare (HC) requires new organizational strategies and systemic medical interventions [1]. The use of information and communication technology (ICT) within healthcare in the domain of entire e-Health [2] grows as a continuing process [3] in which healthcare tasks could be performed using computers and networks to reduce fragmentation of interventions and costs, and to improve communication as well as health outcomes [4]. The advantages of ICT tool applications are not limited to information management and communication processes, the ability to remote access to the services and improved health parameters monitoring, but also in gaining control in chronic disease promoting self-management and decision support and clinical information systems [5].

Among the important features for maintaining health there are socio-economic conditions, although poverty and low levels of education are the most important threats. Health is also one of the fundamental human needs - the need for security and stability plays a leading role in serving the needs of a higher education community (according to Maslow's theory of behaviour) [6].

Demographic changes have a practical impact on the healthcare system and the aging of the population has

Address for correspondence: Zbigniew Wawrzyniak, Department of Health Sciences, NCZ, Medical University of Warsaw, 1A Banacha, Warsaw, Poland

E-mail: magic2k@wp.pl

Received: 05 September 2013; accepted: 02 March 2014 significant effects on the economic side of the healing process, especially for chronically ill patients. The long-term treatment relationship with economic indicators follows, among other things, with the costs of medication and hospitalization of the elderly. In the last five years, the population of patients suffering from chronic disease has increased by $5 \%$, despite the improvement of subjective assessment of health status in Poland [7]. The incidence of such diseases now increases with age, and as many as $82 \%$ of people aged over 50 , are burdened with at least one chronic disease or chronic condition. These will result in an increase in the number of patients using at least four medical visits during the year, and in the number of people taking different medications [7].

\section{OBJECTIVE}

The purpose of the study is to build a systemic concept of the patient environment in which the patient is the central figure in the healthcare system. A new model is presented in which the healthcare of chronic ill patients (CIP) can be improved by using information and communication technologies (ICT). The concept described is a way to realize information management in the chronic disease environment, improved for the patient by using ICT tools and integrate all interactions in an ecosystem of chronic disease management. Usage of ICT tools in an interactive integrated care system is a new and attractive solution of combining personalized healthcare for chronic disease patients with new technologies, achieved 
through: health status monitoring, personal (healthcare educator) and technical support of the patient (mobile/ computer devices and tools, and other technical aids).

\section{MATERIALS AND METHOD}

A study design was chosen as a prospective design, based on the constructive analysis of key information, observation of healthcare processes and organizations, and reviews of other projects. Taking into account the fundamental healthcare goals and legal framework, knowledge of the circumstances surrounding a patient's ecosystem and the patient's needs, allows the construction a new models of care with wider support by ICT. The study material was the process of healthcare for chronically ill patients, considered in the entire ecosystem of all impacts.

Models of care for chronic patient which originated from the model of Weber $[8,9]$ have undergone changes, taking into account the development of the art of medicine, modern technology supporting care, public engagement, and social interactions. The system strives for enhanced chronic care management with better patient and healthcare outcomes from both the functional and clinical aspects, mainly with cost effectiveness and reasonable improvements in the patient's quality of life. In fact, the chronically ill patient and healthcare organizational system affect each other and are subject to interaction with all elements of the surrounding environment, including technical issues. The main factors as a whole environment (ecosystem), chronic disease, practitioner with diagnostics possibilities and medical knowledge (doctor), healthcare organization (as a healthcare system), nonmedical and other cares, emotional and social impact affecting the patient with a chronic disease in a current healthcare system organization. (Fig. 1). Therefore, multifactor interactions should be considered for further technological and organizational improvements.

Tasks of the healthcare system for chronic diseases. Taking comprehensive actions in the lifestyle, environment and

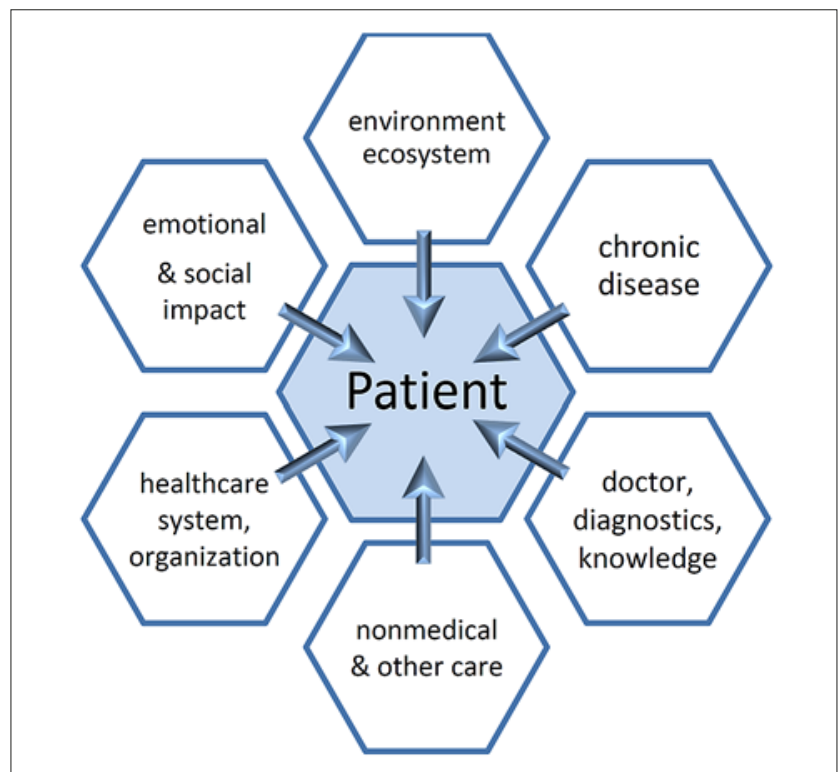

Figure 1. Main factors affecting a patient with a chronic disease in current organization of healthcare system. Source: own protection of the health is a sufficient goal that can help a patient suffering from chronic diseases. For the purpose of the presented study, and in the view of the patients' suffering from a chronic disease (acc. To the official list of chronic disease in Poland) [10], the authors have defined key issues that need to be addressed in order to introduce a new solution (Tab. 1). The solution combines new technologies with the possibility to personalize the art of the care of patients with chronic disease (e.g. chronic coronary artery disease, chronic respiratory diseases, diabetes, allergies).

Table 1. Important issue to be managed for a new solution of combining personalized care to patients with chronic disease with new technologies

\begin{tabular}{|c|c|c|}
\hline Issue & characteristics & improvement \\
\hline $\begin{array}{l}\text { chronic } \\
\text { disease } \\
\text { monitoring }\end{array}$ & $\begin{array}{l}\text { systemic and factorial } \\
\text { approaches to the monitoring } \\
\text { processes }\end{array}$ & $\begin{array}{l}\text { creation and implementation } \\
\text { of measures assessing the } \\
\text { effectiveness of the patient's } \\
\text { care in the HC system } \\
\text { supported by ICT solutions. }\end{array}$ \\
\hline $\begin{array}{l}\text { social care } \\
\text { systems }\end{array}$ & $\begin{array}{l}\text { combination of social } \\
\text { development level and } \\
\text { involvement, and elements of } \\
\text { civil society (the development } \\
\text { of individual and social } \\
\text { activities) }\end{array}$ & $\begin{array}{l}\text { a course of action in } \\
\text { rationalization of the flow } \\
\text { and distribution of financial } \\
\text { resources comprehensively } \\
\text { understood in the direction of } \\
\text { the so-called e-citizen in the } \\
\text { virtual space }\end{array}$ \\
\hline $\begin{array}{l}\text { monitoring } \\
\text { health status }\end{array}$ & $\begin{array}{l}\text { collection and monitoring } \\
\text { data defining appropriately } \\
\text { selected health status and } \\
\text { disease status measures, } \\
\text { and effectiveness in chronic } \\
\text { disease care }\end{array}$ & $\begin{array}{l}\text { implementation of the } \\
\text { collection and monitoring data } \\
\text { supported by the use of ICT } \\
\text { services' methods and means }\end{array}$ \\
\hline $\begin{array}{l}\text { personal and } \\
\text { technical } \\
\text { support of } \\
\text { the patient }\end{array}$ & $\begin{array}{l}\text { patient support need to be } \\
\text { equipped with the knowledge, } \\
\text { technical means and some } \\
\text { organizational skills }\end{array}$ & $\begin{array}{l}\text { introduction of the new } \\
\text { element the } \mathrm{HC} \text { educator- } \\
\text { (functionally like coach or } \\
\text { animator), equipped with } \\
\text { the appropriate knowledge, } \\
\text { technical ICT means and } \\
\text { supported by the HC } \\
\text { organization to teach patient } \\
\text { systemically about chronic } \\
\text { disease self-management; an } \\
\text { integral part of the HC system } \\
\text { and organizations }\end{array}$ \\
\hline $\begin{array}{l}\text { patient } \\
\text { management }\end{array}$ & $\begin{array}{l}\text { patient monitoring and } \\
\text { management by the } \\
\text { HC system to improve } \\
\text { performance and prevent } \\
\text { deterioration of health status } \\
\text { in chronic diseases }\end{array}$ & $\begin{array}{l}\text { introduction of the patient } \\
\text { self-management effectively } \\
\text { into the HC system support; the } \\
\text { term of self-management for } \\
\text { the patient means the essential } \\
\text { characteristics to practically } \\
\text { support of self-care }\end{array}$ \\
\hline $\begin{array}{l}\text { patient role } \\
\text { in the system }\end{array}$ & $\begin{array}{l}\text { the patient is the central } \\
\text { element of the system (the } \\
\text { patient-centered system) with } \\
\text { the accompanying processes } \\
\text { of information exchange and } \\
\text { HC services }\end{array}$ & $\begin{array}{l}\text { transfer essence of HC service } \\
\text { in the patient-centered system } \\
\text { with the accompanying } \\
\text { processes of information } \\
\text { exchange and HC services; } \\
\text { a more patient-centered } \\
\text { approach improves health } \\
\text { outcomes, particularly in } \\
\text { chronic conditions }\end{array}$ \\
\hline
\end{tabular}

Source: own but based on ideas of [9]

The proposed method of building a new organization model of healthcare requires, firstly, an analysis of the surrounding environment, and other factors that could improve a patient's living conditions. As a research method, a constructive analysis was used and the creation of a system environment description of the patient's life. 
An the environment of a patient with a chronic disease is a set of factors which, for existing legal models, are reduced to current systems of the model of healthcare system organization - Chronically Ill Patient (CIP) (Fig. 2). The central element of the system is the patient, who due to his chronic disease requires long-term, medical and nonmedical care (Fig. 1).

Care systems, based on legal and administrative basis (nonhuman factors), are the structure of the system's framework in which healthcare takes place. Knowledge, as a result of the decisions made during the diagnostic process, and the outcomes of treatment based on the principle of Evidenced Based Medicine (EBM), is used by medical personnel with the support of technical aids, mainly ICT tools and systems.

Evaluation of the healthcare system effectiveness as an internal target of the described system is an additional feature of the knowledge assessment and management.

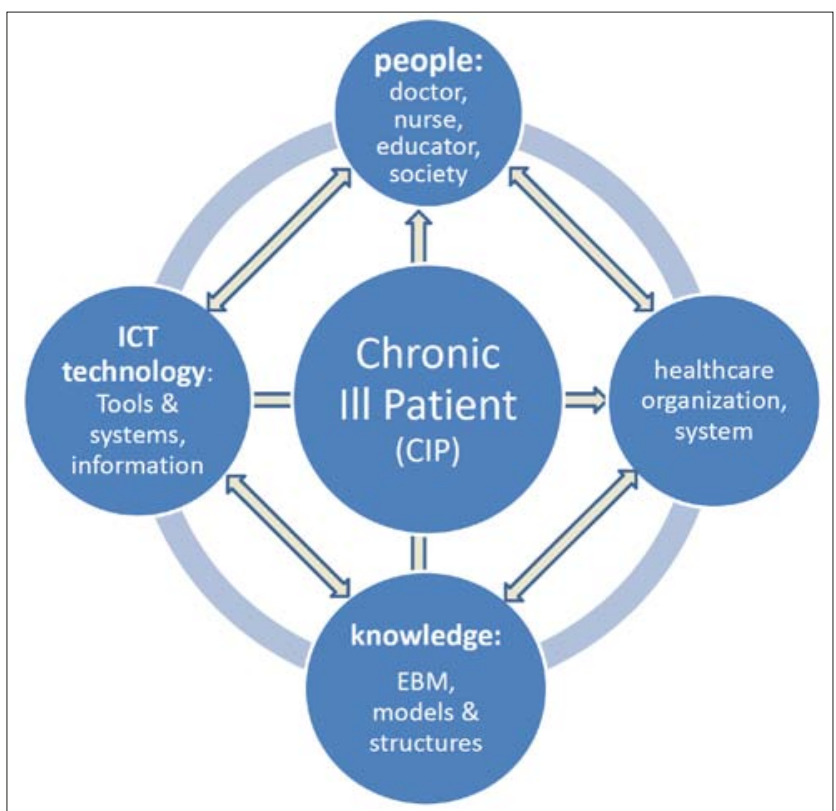

Figure 2. Model of the healthcare system for Chronically III Patient (CIP) in terms of its main respective factorial functions for the new organizational model. Source: own

Healthcare innovative tasks for the new model. The model could be implemented as an organizational and technical support for the care of the patient with chronic disease within the healthcare system. Particularly, the highlighted priorities of [12] for the new model are the following: development of methods and technologies: 1) for general health-enhancing physical education, 2) for prevention, diagnosis and treatment of diseases related to the elderly, and 3) development of telemedicine systems.

Having analyzed the current state of knowledge, the systemic approach to healthcare in the care model requires defining and dividing groups of these factors into processes in order to optimize their health and social consequences, including efficiency. The patient (as a subject) as the central element (unlike the system-oriented itself) is the effect of interactions and reactions on the part of the environment ecosystem, social and emotional factors and healthcare system, as the process of executing their duties on the patient. An applied knowledge obtained from the diagnostic process conducted by medical personnel is a functional unity of objectives and means.
Chronic disease, although allocated to the patient by its rules which are the subject of ongoing learning processes, treatment, diagnosis and medical research based on EBM rules, there are also other distributed factors (except as indicated and debated in the presented study), which in the process of patient care cannot be neglected, even though they are not widely used. Assigning new technical and organizational roles will be the subject for further constructive analysis and constructing a new healthcare model with the support of ICT tools.

The specificity of system solutions in chronic diseases. In the presented considerations, the rule that the potential of society lies in the proposed innovation and competitive solutions of public organizations providing services in the area of healthcare for chronically ill patients $[11,13]$. In the present analysis it was adopted that the social responsibility of the person for his/her health (as the hypothetical patient) increases through direct participation in the control of his/ her own health because of its internal or external location. The general construct of Locus of Control (LoC) specifically refers to health LoC [14]. It is assumed that the internal health LoC is associated with the adoption of more responsibility for its health, which in turn is good health. External health LoC is divided into two types, namely, the impact of other humans or an event on health. When it comes to it, the creation of new health behaviours for healthy people, internal control is based on the responsibility for their own health and initiation of specific health behaviours. This is definitely more beneficial to health than an external audit, which is based primarily on the influence of others than with action. Preference for external control is much more common in people with chronic illness [14].

\section{RESULTS}

The focus of attention in this study is the patient, his/her longterm treatment, and the resultant data from monitoring that create a virtual patient model (VPM), both collective in social meaning, and individual. VPM creates a system-level solution and the individual layers of services and devices, including the category of biosensors measuring parameters of the disease and/or the patient's outcomes $[15,16]$. The patient's model as a whole system requires the integration and fusion of the elements from both the information and management's points of view to gather and manage the knowledge.

Design of the integrated healthcare system for chronic disease patients. This concept will be carried out in the framework of individual meetings/contacts with the HC educator employed in the healthcare organization or care provider, and the virtual educator (based on a VPM by using ICT tools), 'watching' the patient under the personalized healthcare in the course of an individual chronic patient. The information system - based on web/mobile/computer networks and platforms - will manage large volumes of heterogeneous data about a patient's health status, clinical evaluation resulting from the data of different biosensors placed on the patient body, or other external sensors.

The proposed VPM and its elements will expand medical knowledge based on ex ante knowledge and results obtained from monitoring. This pioneering solution designates 
standards for systemic remote control of chronically ill patients under the healthcare, both individually and collectively.

Self-management in the entire proposed concept will mean a set of activities and patient's activity within a broad range of needs and tasks as a result of the disease requirements, as well as full social activity and integration with society. In some chronic diseases, physical and mental impairment can lead to changes in a patient's social role, including their limitation or exception, and even self-exclusion. Into this process of changing a patient's role in the disease ecosystem, the $\mathrm{HC}$ educator will be introduced for both personal (human) and virtual manners. Therefore, the value assessment will be subject to individual assessment, and the force of $\mathrm{HC}$ educator persuasion, as well as both traditional and virtual tools based on ICT. Evaluation of the improved HC model will be performed in the real systems of healthcare regimens for individual patients with selected chronic diseases.

Therefore, the patient's involvement in the process of control/management of own health due to internal or external LoC, and the way of conducting healthcare, are important. The role of the $\mathrm{HC}$ educator with assigned tasks as part of the healthcare organization and system is summarizes in Table 2. Educational and organizational tasks incumbent on the 'HC educator' mainly assume the same competence level as graduates of Public Health from Medical Universities. The main function of the $\mathrm{HC}$ educator is to animate patient activity at the junction of the factors affecting the patient internally and externally - from the system, society and the environment. The HC educator personally impacts the patient through the process of disease management. Improvement in living conditions as a final result requires monitoring of the patient health parameters and external factors affecting the entire environment of chronic disease.

The new model of patient care is also based on using the approach involving new actors (entities) and processes implemented in order to improve the basic living conditions as primary objectives. Processes of chronic disease treatment and care are supplemented by new chronic disease management processes associated with providing new knowledge from monitoring results, and from the healthcare system.

The philosophy of the care of patients with chronic disease is based on the following entities (Fig. 3):

- user-oriented model (patient-oriented model): in contrast to the existing system-oriented solutions, this based on

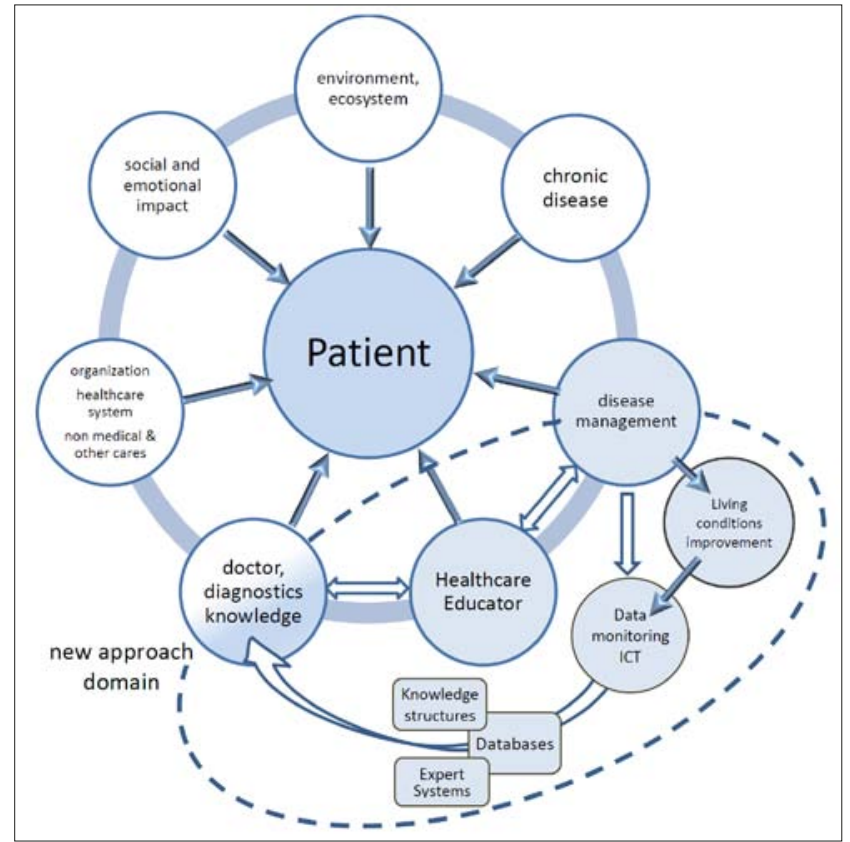

Figure 3. Improved technical and organizational model of healthcare effects on the patient as part of healthcare ecosystem for chronically ill patient to improve his living conditions. Source: own

knowledge management and the aggregation of new knowledge generated in the monitoring process, and by the fusion of knowledge from other sources and a doctor's decision based on medical diagnosis process and access to other sources of developing EBM knowledge, including emotional aspects, psychological knowledge, social prevention and patient-oriented prophylactics

- organizational and technical system: based on the combination of existing healthcare-system processes and associated complimentary components (taking into account the current and proposed solutions); however, the model is enforced and modified by the legal conditions (legal framework);

- concept of the entire system: based on the task assumption of protectiveness over whole ecosystem, leading the patient to start own resources by himself/herself, and to be supported personally with technical tools from other links in the system, substantially including ICT tools and systems;

Tabela 2. The role of $\mathrm{HC}$ educator as part of the $\mathrm{HC}$ system

\begin{tabular}{lll}
\hline Function & Tasks/ & Description \\
\hline educational and organizational & $\begin{array}{l}\text { help in being familiar with the new } \\
\text { situation of disease }\end{array}$ & $\begin{array}{l}\text { chronic disease needs a long-term care (not only medical) as a part of the patient's entire } \\
\text { life }\end{array}$ \\
\hline educational and organizational & $\begin{array}{l}\text { understanding wizard of the new } \\
\text { patient's state }\end{array}$ & $\begin{array}{l}\text { development of a constructive approach to solve all the question of his needs - medical } \\
\text { and nonmedical aspects }\end{array}$ \\
\hline educational and organizational & patient's education & education scope would cover his disease and its associated problems \\
\hline educational & use of available aids & $\begin{array}{l}\text { featuring the patient with the proper variety of tools which enables him to deal with the } \\
\text { disease, including technical support of ICT tools }\end{array}$ \\
\hline organizational & $\begin{array}{l}\text { monitoring and measuring the } \\
\text { disease/health status parameters }\end{array}$ & $\begin{array}{l}\text { practical education in the use of available aids, especially on the level of practical } \\
\text { rules, tools, equipment, other facilities that help him to live with the disease and to } \\
\text { standardize the conditions of living }\end{array}$ \\
\hline status parameters directly by the patient.
\end{tabular}


- hardware systemic control: sensing and monitoring the factors and parameters realized by different measuring devices (meters) and ways of monitoring (depending on the type of disease and characteristics of chronic disease severity);

- HC educator's role: mainly educating, activating, reporting and managing, but also in terms of legal competences and his placement in healthcare organization;

- resultant databases (approaching knowledge structures): include various indirect sources of information (demographic, health status and specialized epidemiological databases, and the databases of monitored parameters) and direct sources (decision support systems and disease processes evolution).

The centrally-located patient for whom external factors interact manages the disease with the help of the entire healthcare system, and supported by the HC educator to improve living conditions. The internal penetration of layers and technical means exploit synergies, while at the same time it does not limit the development of new forms at the interface of the existing types of patient activity, and the entire ecosystem.

Interactions and relationships between databases on their different ontological levels create an efficient tool which supports physicians and $\mathrm{HC}$ educator while providing opportunities to support patient himself and interactive process of data and knowledge modeling. Prediction in forecasting and information support in decision making (as expert systems) are carried out by developing models of the disease (in virtual chronic patient model, VCP) and of the life processes (in virtual physiological human model, $\mathrm{VPH}$ ). The advantage of chronic disease evaluation will be creating the fusion of all data elements of the entire model (VCP and VPH), and forecasting development of the disease at the level of the patient's care and organization (Fig. 4).

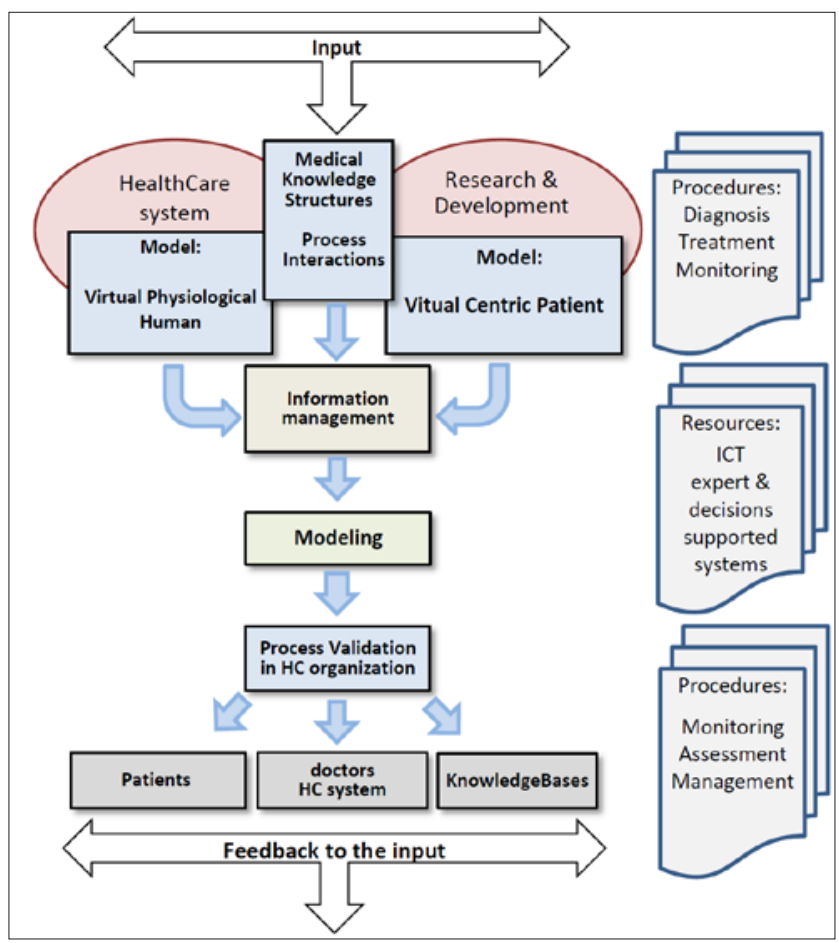

Figure 4. Functional model of information management for virtual patient with chronic disease (VCP) within the healthcare organization. Source: own
Both issues take healthcare within the public health system of chronic patients and society.

In the development of the idea of the project described, the latest achievements in ICT and in medical technologies will be successively applied. The concept of this model will be conducted in cooperation with industrial partners/ branches in the medical field, for example, NGO and social organizations implemented within the public healthcare system, including those of chronic disease patient care in Poland.

Based on the above-mentioned assumptions, steps are proposed for actions leading to the development and practical implementation of the system (Tab. 3.). The size of the patient's scale will enhance the efficiency of patient-associated care, including the specificity of the proposed chronic diseases.

Table 3. Steps for action leading to development and practical implementation of new system

\begin{tabular}{ll} 
Step & Aim \\
\hline Linking & $\begin{array}{l}\text { Linking patient with the surrounding environments of social, } \\
\text { nonmedical and medical services }\end{array}$ \\
\hline Efficiency & $\begin{array}{l}\text { Comparison of organizational and technical efficiency measures } \\
\text { for specific diseases in implementation for long-time period and } \\
\text { the stabilization of the system operation. }\end{array}$ \\
\hline Model & $\begin{array}{l}\text { Adjustment of the model characteristics to specific needs of } \\
\text { the chronic disease monitoring and its measurement system } \\
\text { instrumentation for the information exchange of between the } \\
\text { elements of the new developed care model and knowledge } \\
\text { databases under construction in process of data collection. }\end{array}$ \\
\hline $\begin{array}{l}\text { Model } \\
\text { Validation }\end{array}$ & Validation of the model system during project life cycle \\
\hline
\end{tabular}

Source: own

\section{CONCLUSIONS}

1) Based on the systemic approach to the chronic disease patient's model and to the overall model of chronic disease, a new model of whole interactions and an interaction ecosystem with information feedback can be built. In the provision of services, the exchange of information based on ICT technologies and supported actions play a key role in the system's objectives for the patient.

2) ICT systems lead to the integration of the services provided in terms of care continuity at the edge of the patient and the chronic disease with various functions and system parameters of cooperating components of healthcare. Organizational integration of information exchange combines strictly medical service with non-medical services as welfare care and social services (including social networks) that streamline the entire management. This increases efficiency and productivity of the entire healthcare system from the view point of the service output effects of the healthcare system on a chronically ill patient, such as: patient's satisfaction, life and care quality (including DALE and QALY measures).

3) An increase could be observed in the effectiveness of diagnostic and therapeutic processes and treatment of chronic disease in the healthcare system by supporting patient self-management. The taking-care environment of the patient as well as appropriate care information providing a sense of security will effectively reduce the 
cost of caring for a patient in the course of chronic disease, and improve the quality of service. In the long-term, the lowering the social costs of healthcare for chronically ill patients is attractive and efficient.

4) Appropriate tools, also tailored to individual patient needs and taking into account the chronic disease, allow the patient to monitor and measure relevant indicators which provide information and a sense of security.

5) Enrichment in the form of cooperation under the processes of patient's diagnosis, therapy and treatment by using modern ICT tools and information exchange, increase patient involvement in the diagnostic and therapeutic course.

6) The healthcare system is directed at focusing patient selfmanagement in chronic disease with the support of $\mathrm{HC}$ educator acting as part of a healthcare system in a healthcare organization. The HC educator serves alternatively in an advisory role as an animator and designer of the patient's active life. His activity is a part of the coordinating tool in information exchange, ensuring the safety, awareness of patient needs, and self-management in chronic disease conditions that personalize the system of healthcare for a chronically ill patient.

For implementation of this concept, it is observed that the current healthcare system does not have a full model of care, among other things, also because the non-funding of certain types of ancillary services, and the system of the State healthcare organization does not fully specify a packet of essential and ancillary benefits for the patient.

\section{REFERENCES}

1. Wollersheim H, Faber M. Better affordable care; a framework to analyse and improve integrated care delivery. Int J Care Pathways. 2012; 16: 92.

2. van Gemert-Pijnen JE, Nijland N, van Limburg M, Ossebaard HC, Kelders SM, Eysenbach G, et al. A holistic framework to improve the uptake and impact of eHealth technologies. J Med Internet Res. 2011; 13(4): e111. Epub 2011 Dec 05
3. Busse R, Blumel M, Scheller-Kreinsen D, Zentner A. Tackling Chronic Disease in Europe. Strategies, Interventions and Challenges. World Health Organization, Copenhagen, 2010.

4. Lindberg B, Nilsson C, Zotterman D, Söderberg S, Skär L. Using Information and Communication Technology in Home Care for Communication between Patients, Family Members, and Healthcare Professionals: A Systematic Review. Int J Telemed Appl. 2013; 2013:461829. doi: 10.1155/2013/461829. Epub 2013 Apr 10.

5. Oxman AD, Bjørndal A, Flottorp S, Lewin S. Lindahl AK. Integrated Health Care for People with Chronic Conditions. Nasjonalt kunnskapssenter for helsetjenesten. Oslo, 2008.

6. Hall CS, Lindzey G, Campbell JB. Theories of Personality. Oxford University Press, London, 2004.

7. Szymborski J. Future demographic and health. Presentation of the European Economic Congress - the third day 2012-05-16, http://www. wnp.pl/pliki/4177.html (access: 2013.04.02).

8. Improving Chronic Illness Care. http://www.improvingchroniccare. org/index.php?p=The_Chronic_Care_Model\&s=2 (access: 2013.07.02)

9. Stuckey HL, Dellasega C, Graber NJ, Mauger DT, Lendel I, Gabbay RA. Diabetes nurse case management and motivational interviewing for change (DYNAMIC): Study design and baseline characteristics in the Chronic Care Model for type 2 diabetes. Contemp Clin Trials. 2009; 30: 366-374.

10. List of chronic diseases - in accordance with the Regulation of 2009. Dz.U. 2009, No. 212, item. 1647, http://www.infor.pl/dziennikustaw,rok,2009,nr,212/poz,1647,rozporzadzenie-ministra-zdrowia-wsprawie-wykazu-chorob-oraz-wykazu-lekow-i.html (access: 2013.07.02)

11. Gaspar R, Aksu B, Cuine A, Danhof M, Jadrijevic-Mladar Takac M, Linden HH, Link A. et al. Towards a European Strategy for Medicines Research (2014-2020) - The EUFEPS Position Paper on Horizon 2020. Eur J Pharm Sci. 2012; 47(5): 979-987.

12. National Health Program for the years 2007 to 2015. (in Polish Narodowy Program Zdrowia na lata 2007 - 2015), Annex to Resolution Nr 90/2007 Council of Ministers of 15 May 2007. http://www.mz.gov. pl/wwwfiles/ma_struktura/docs/zal_urm_npz_90_15052007p.pdf, (access: 2013.07.02).

13. Epping-Jordan JE, Pruitt SD, Bengoa R, Wagner EH. Developing research and practice: Improving the quality of health care for chronic conditions. Qual Saf Health Care. 2004; 13(4): 299-305.

14. Rotter JB. Social learning and clinical psychology. Engelwood Cliffs, NJ Prentice Hall, 1954.

15. Castiglione F, Diaz V. Physio-environmental sensing and live modeling and the role of U-CEP. http://www.academia.edu/1260053/Physioenvironmental_sensing_and_live_modelling_and_the_role_of_UCEP (access: 2013.07.02).

16. Castiglione F, Diaz V, Gaggioli A, Liò P, Mazzà C, Merelli E, et al. Physio-Environmental Sensing and Live Modeling. Interact J Med Res. 2013; 2(1): e3. 